\title{
DIREITOS DECISÓRIOS E DE CONTRIBUIÇÃO NAS ESTRATÉGIAS DE TI: ESTUDO EM UMA EMPRESA DE GRANDE PORTE NO ESTADO DO RS
}

\author{
Decision-making rights and contribution in IT strategies: Study in a \\ large company in the State of RS
}

Karen Hackbart Souza Fontana

E-mail: karen.hsfontana@gmail.com

Mestra em Ciências Contábeis pela Universidade do Vale do Rio dos Sinos;

Especialista em Controladoria e Finanças pela Instituição Educacional São Judas Tadeu;

Professora na Faculdade Cesuca Inedi.

Endereço para contato: Rua Silvério Manoel da Silva, 160, Colinas, 94935-630, Cachoeirinha, Rio

Grande do Sul, Brasil.

https://orcid.org/0000-0002-4932-3738

Geruza Rodrigues Thiel

E-mail: geruza.thiel@gmail.com

Mestra em Ciências Contábeis pela Universidade do Vale do Rio dos Sinos;

Especialista em Ciências Contábeis pela Universidade Federal do Rio Grande; Professora e

Coordenadora na Pontifícia Universidade Católica de Pelotas.

https://orcid.org/0000-0002-7800-2888

Adolfo Alberto Vanti

E-mail: adolfo.vanti@san.uri.br

Doutor em Direção de Empresas/Administração pela Universidad de Deusto-País Vasco, Espanha; Mestre em Administração pela Universidade Federal do Rio Grande do Sul; Professor na Universidade Regional Integrada do Alto Uruguai e das Missões. https://orcid.org/0000-0001-5176-2572

Pedro Solana González

E-mail: pedro.solana@unican.es

Doutor em Engenharia Industrial pela Universidad de Cantabria; Mestre em Matemática Aplicada

e Ciência da Computação pela Universidad de Cantabria; Professor na Universidad de Cantabria. https://orcid.org/0000-0001-5606-1476

Artigo recebido em 18 de abril de 2018. Aceito em 8 de outubro de 2019. 


\section{Resumo}

Este artigo teve como objetivo analisar, por meio da matriz de arranjos de governança e arquétipos políticos abordados por Weill e Ross (2006), a participação de gestores nos direitos decisórios e de contribuição nas estratégias de TI em uma empresa de grande porte no Estado do RS. Trata-se de um estudo descritivo, qualitativo, delineado por meio de um estudo de caso. Os resultados encontrados apontaram que a maioria das decisões-chave relacionadas à Governança de TI são tomadas por Duopólio de TI. O Duopólio consiste em decisões estratégicas de TI por meio de executivos de TI conjuntamente a algum outro grupo da empresa, por exemplo, $\mathrm{CxO}$ s ou líderes de unidades de negócios. Com relação à contribuição para a tomada de decisão, percebe-se que o arquétipo predominante é a Monarquia de TI, ou seja, a participação exclusiva de indivíduos ligados à área de TI. Notase, dessa forma, o forte envolvimento de profissionais de TI no processo decisório da empresa estudada. Essa parceria entre administradores seniores e líderes de TI no processo decisório pode auxiliar o alinhamento entre TI e estratégias de negócios e fornecer expectativas realistas para a Tl.

Palavras-chave: Governança de TI. Direitos decisórios e de contribuição. Estratégias de TI.

\section{Abstract}

This article aimed to analyze, through the array of governance arrangements and political archetypes covered by Weill and Ross (2006), the participation of managers in decisionmaking rights and contribution strategies in a large company in the Rio Grande do Sul State. This is a descriptive study, qualitative, delineated by means of a case study. The results showed that most of the key decisions related to governance are taken by Duopoly. The Duopoly consists of strategic decisions you through IT executives together to any other group company, for example, $\mathrm{CxO}$ or leaders of business units. In relation to the contribution to the decisionmaking process, the archetype is the Monarchy of you, namely, the exclusive participation of individuals linked to IT. Note this shape, the strong involvement of professionals in the decision-making process of the company. This partnership between senior administrators and IT leaders in the decision-making process can help the alignment between IT and business strategies and provide realistic expectations for IT.

Keywords: IT Governance. Decision-making rights and contribution. IT Strategies.

\section{INTRODUÇÃO}

O uso da Tecnologia da Informação possibilita o sucesso nos negócios, pois automatiza as tarefas, melhora a performance e qualidade dos serviços, além de permitir o reconhecimento de um problema antecipadamente (Moura, Lima, Pinto, \& Rocha, 2018). Destaca-se a Tl quanto à evolução das tecnologias e sua inclusão no cotidiano das empresas (Putz, Rasoto, \& Ishikawa, 2017), bem como na disponibilidade de informações à gestão organizacional para a tomada de decisão e gerenciamento do negócio (Moura et al., 2018).

Para alinhar as estratégias de negócio às estratégias de TI se evidencia a Governança de Tecnologia da Informação. A Governança de Tecnologia da Informação (GTI) busca esse alinhamento por meio da integração de recursos e maior profissionalismo quanto aos processos decisórios (Mendonça, Souza, \& Guerra, 2013). Conforme Affeldt e Vanti (2009), 
- alinhamento estratégico pode proporcionar a visualização das informações estratégicas, bem como posicionar a área de Tl e os sistemas de informação como elementos-chave dentro das empresas.

De acordo com Santos (2018), "a GTI tem despertado um crescente interesse no meio acadêmico e nas organizações, refletindo a importância e a evolução da TI na sociedade contemporânea" (p. 73). Corroborando, Assis e Laurindo (2010) comentam que a GTI tem atraído crescente interesse de pesquisadores e executivos, dada a importância da Tecnologia da Informação (TI) no ambiente empresarial. A Tecnologia da Informação (TI) pode ser entendida como o uso intensivo do recurso informação e das tecnologias associadas à sua captação, armazenamento, tratamento e disseminação (Fresneda, 1998).

Como forma de melhorar o gerenciamento da TI, a Governança de TI tem se tornado essencial para o alcance dos objetivos corporativos, uma vez que proporciona estruturas de liderança, processos e mecanismos organizacionais que possibilitem que a TI sustente e apoie o negócio. Para assegurar o alinhamento com a estratégia e os objetivos da organização, um dos papéis da Governança de TI é estabelecer quem possui os direitos e responsabilidades de decisão quanto às determinações, como, por exemplo, de investimentos em TI (Hiekkanen et al., 2013).

Iniciativas e frameworks em Tl, a fim de agregarem valor ao negócio, têm sido abordados por estudos empíricos principalmente pela obra clássica de Weill e Ross (2006). Os autores apresentam, entre suas descobertas, uma ferramenta simples e prática para avaliar processos decisórios e de contribuição para estimular comportamentos desejáveis no uso da TI.

Por meio de uma Matriz de Arranjos de Governança e arquétipos políticos, Weill e Ross (2006) descrevem as combinações de pessoas que têm direitos decisórios elou contribuem para a tomada de decisão. As decisões da administração e TI são harmonizadas pela Governança de TI (GTI) e, de acordo com os autores, empresas de melhor desempenho têm sucesso no que as outras fracassam porque implementam uma Governança de Tl eficiente para sustentar suas estratégias.

Há diversas pesquisas empíricas que tratam sobre a GTI. Há estudos realizados sobre benefícios da TI e a relação com o desempenho empresarial (Albertin \& Albertin, 2008); utilização dos critérios de efetividade da GTI (Sortica \& Graeml, 2009); adoção das práticas de modelos de GTI (Barbosa, Araújo, \& Torres, 2011; Tarouco \& Graeml, 2011); gerenciamento e controle de operação (Luciano \& Testa, 2011); mecanismos para melhorar o desempenho financeiro (Lunardi, Becker, \& Maçada, 2012); revisão da literatura sobre recursos de TI sob as diferentes correntes de pesquisa e frameworks de governança (Hiekkanen et al., 2013); sistema de apoio à tomada de decisão inteligente (Arshad, Ahlan, \& Ajayi, 2014); impactos gerados nos processos de trabalho (Klumb \& Azevedo, 2014); ferramenta na 
gestão de negócios (Duarte, Kipper, Paz, \& Mariani, 2015); resolução de conflitos e eficiência na implementação e consecução de objetivos de negócios em programas de TI (Parolia, Jiang, Chen, \& Klein, 2015); análise da dimensão alinhamento estratégico nas Universidades Federais Brasileiras (Putz et al., 2017); e benefícios da TI para as estratégias empresariais (Moura et al., 2018).

Estudos quanto à temática de arquétipos nos direitos decisórios e/ou de contribuição da mesma forma foram identificados (Assis \& Laurindo, 2010; Mendonça et al., 2011; Mendonça et al., 2013; Pereira, Macadar, \& Daniel, 2013), porém, de forma menos expressiva e com resultados que não são totalmente convergentes, ou seja, em algumas decisões-chave não se percebe uniformidade entre as práticas utilizadas pelas empresas.

Diante desse contexto e a fim de propor uma reflexão entre a perspectiva de estudos já realizados e práticas recentes, tem-se a seguinte questão de pesquisa: como é a participação de gestores nos direitos decisórios e de contribuição nas estratégias de Tl em uma empresa de grande porte no Estado do RS?

Esta pesquisa justifica-se por proporcionar o conhecimento dos arquétipos predominantes no direcionamento estratégico da Tl, ao analisar a participação de gestores nos direitos decisórios e de contribuição nas estratégicas de TI em uma empresa de grande porte no Estado do RS. Conforme Mendonça et al. (2013):

o aumento da importância da TI acarreta a reflexão e uma maior atenção em questões vinculadas ao crescimento de investimentos em $\mathrm{Tl}$, valor que a $\mathrm{Tl}$ agrega à organização e a seus produtos e serviços. Desse modo, torna-se necessária uma sincronização entre o Negócio e a $\mathrm{Tl}$, e em consequência uma administração dos recursos de TI, principalmente devido aos altos investimentos, à dificuldade de mensurá-los e definir como e quem são os atores do processo decisório (p. 444).

Outra justificativa de acordo com Mendonça et al. (2013) é que mesmo com a importância teórica do tema, são escassos os estudos de caso que analisam o processo decisório na área de $\mathrm{Tl}$, sendo grande parte dos estudos concentrados em analisar as tecnologias propriamente ditas, a estrutura da Tecnologia da Informação e a importância da TI para as organizações. Segundo Weill e Ross (2006), representar e analisar os direitos decisórios é fator crítico de sucesso para a Governança de TI.

Este artigo está estruturado em cinco seções. A primeira proporciona esta introdução; a segunda seção aborda a revisão da literatura; a terceira expõe os procedimentos metodológicos; a quarta explana os resultados encontrados; e a quinta, a conclusão deste trabalho sobre os resultados da pesquisa. Na sequência apresentam-se as referências utilizadas no desenvolvimento do estudo. 


\section{REVISÃO DA LITERATURA}

\subsection{GOVERNANÇA DE TECNOLOGIA DA INFORMAÇÃO (GTI)}

A Governança de Tecnologia da Informação (GTI) é um meio para utilizar de forma eficiente e eficaz a TI (Bin-Abbas \& Bakry, 2014). De acordo com Fresneda (1998), a Tecnologia da Informação ( $\mathrm{TI}$ ) pode ser entendida como o uso intensivo do recurso informação e das tecnologias associadas à sua captação, armazenamento, tratamento e disseminação. A TI é destacada à medida que há a evolução tecnológica e sua inclusão no cotidiano das empresas (Putz et al., 2017).

Nesse sentido, o recurso informação sempre esteve presente nas organizações, independentemente de segmento ou porte, cumprindo importante papel para a gestão do negócio, proporcionando apoio à tomada de decisão. Para Sêmola (2014), os efeitos da Tecnologia da Informação aplicada ao negócio podem objetivar aumento de agilidade, competitividade, redução de custos, melhor produtividade, etc. Para Fink e Ploder (2008), o papel de TI é transmitir desde uma ferramenta de apoio até um recurso de vantagem competitiva.

Dessa forma, a GTI busca direcionar a TI para atender ao negócio em conformidade com o direcionamento tomado pela organização (Fernandes \& Abreu, 2014). A GTI oportuniza a geração de informações mais confiáveis, seguras e alinhadas à estratégia da organização, auxiliando a qualidade da informação utilizada para a tomada de decisão. De acordo com Fernandes e Abreu (2014), a informação é um recurso-chave para qualquer empresa e a tecnologia tem papel importante durante todo o seu ciclo de vida.

A necessidade de GTI surgiu com base no fato de que as organizações têm de pensar na Tl e sua infraestrutura além de um departamento, e que deve haver justificativas maiores para o orçamento comprometido com o sustento de tais produtos e serviços de TI. Assim, tendo em conta esse cenário, a GTI concentra-se na realização e transformação de recursos para atender às demandas atuais e futuras do processo de negócio (foco interno) e clientes do negócio (foco externo). O controle exercido pelo Conselho de Administração e gerências, na formulação de decisões corretas, permite a criação de estruturas e processos que sustentem assim as melhores práticas, a fim de adaptá-las para permitir o alinhamento estratégico da TI com o negócio, garantindo que as organizações de TI possam estender suas estratégias e objetivos a uma utilização ótima de seus recursos, percebida por seus usuários gerenciados, levando a um bom desempenho corporativo (Arshad et al., 2014).

Conforme Thompson, Ekman, Selby, \& Whitaker (2014), as organizações buscam centralizar processos de TI na tentativa de mitigar riscos, otimizar a alocação de recursos, 
satisfazer usuários, melhorar controles internos e aproximar a estratégia empresarial ao uso da TI. A governança garante que as necessidades, condições e opções das partes interessadas sejam avaliadas a fim de determinar objetivos corporativos acordados e equilibrados, definindo o direcionamento por meio de priorizações e tomadas de decisão, monitorando o desempenho e a conformidade com os objetivos estabelecidos, enquanto que a gestão de TI se torna responsável pelo planejamento, desenvolvimento, execução e monitoramento das atividades em consonância com a direção definida pelo órgão de governança com a finalidade de atingir os objetivos corporativos (IT Governance Institute [TTGI], 2012). De acordo com Weill e Ross (2006):

a Governança de TI é a especificação dos direitos decisórios e do framework de responsabilidades para estimular comportamentos desejáveis na utilização da TI. A Governança de TI não consiste na tomada de decisões específicas sobre a $\mathrm{TI}-\mathrm{a}$ administração já faz isso-mas determina quem sistematicamente toma tais decisões e contribui para elas (p. 2).

Segundo Lunardi et al. (2012), a governança de Tl é bem mais ampla que a gestão da $\mathrm{TI}$, pois envolve todas as questões da organização relacionadas à tecnologia, desde a definição de políticas, direitos e responsabilidades sobre as decisões de $\mathrm{TI}$, passando pela aprovação de investimentos e projetos tecnológicos, pelo monitoramento e manutenção da $\mathrm{Tl}$ existente, até chegar à avaliação do valor entregue pela TI à organização. De acordo com - ITGI (2007), os elementos-chave que constituem a Governança de TI são: a avaliação do valor de $\mathrm{Tl}$ e o gerenciamento dos riscos relacionados à $\mathrm{Tl}$ e às crescentes necessidades de controle sobre as informações.

Fernandes e Abreu (2014) complementam o entendimento desses elementos-chave, discorrendo que a Governança de TI busca, além do compartilhamento das decisões de TI com os demais dirigentes da organização, o estabelecimento de regras de organização e dos processos que norteiam o uso da TI pelos usuários, departamentos, divisões, negócios da organização, fornecedores e clientes, e ainda determina como a $\mathrm{TI}$ deve prover os serviços para a organização. Desse modo, a GTI deve atender, segundo os autores, aos seguintes requisitos: garantir o alinhamento da TI ao negócio; garantir a continuidade do negócio contra interrupções e falhas; e garantir o alinhamento da $\mathrm{TI}$ aos marcos de regulação externos.

A GTI tem despertado um crescente interesse acadêmico e profissional, pois evidencia a relevância e a evolução da TI na sociedade atual (Santos, 2018). 


\subsection{MATRIZ DE ARRANJOS DE GOVERNANÇA DE TECNOLOGIA DA INFORMAÇÃO (TI)}

A Matriz de Arranjos de Governança de TI é um modelo proposto por Weill e Ross (2006) que possibilita a verificação de quem são os tomadores de decisão, bem como os contribuintes para as decisões-chave de $\mathrm{TI}$. $\mathrm{O}$ modelo permite compreender como as empresas governam a TI.

Weill e Ross (2006) apresentam a Matriz de Arranjos de Governança de TI como uma ferramenta para projetar a governança das empresas com base em cinco decisões críticas de TI. As decisões críticas são denominadas como arranjos e classificadas da seguinte forma: Arranjos de governança típicos para princípios de Tl; Arranjos de governança típicos para a arquitetura de $\mathrm{Tl}_{\text {; }}$ Arranjos de governança típicos para estratégias de infraestrutura de $\mathrm{Tl}_{\text {; }}$ Arranjos de governança típicos para necessidades de aplicações de negócio; e Arranjos de governança típicos para investimentos e priorização de TI. A Tabela 1 apresenta as descrições dos Arranjos de TI:

Tabela 1

Descrição dos arranjos típicos de $\mathrm{TI}$

Decisões-chave

Descrição

Decisões sobre os princípios de TI Declarações de alto nível sobre como a TI é utilizada no negócio.

Decisões sobre a arquitetura de TI

Decisões sobre a infraestrutura de TI

Necessidades de aplicações de negócio

Decisões sobre os investimentos e a priorização da $\mathrm{TI}$
Organização lógica de dados, aplicações e infraestruturas definidas a partir de um conjunto de políticas, relacionamentos e opções técnicas adotados para obter a padronização e integração técnicas e de negócios desejadas.

Serviços de TI coordenados de maneira centralizada e compartilhados, que proveem a base para a capacidade de TI da empresa.

Especificação da necessidade de negócio de aplicações de TI adquiridas no mercado ou desenvolvidas internamente.

Decisões sobre quanto e onde investir em TI, incluindo a aprovação de projetos e as técnicas de justificação.

Nota. Adaptada de "Governança de tecnologia da informação: Como as empresas com melhor desempenho administram os direitos decisórios de TI na busca por resultados superiores," por P. Weill e J. W. Ross, 2006, São Paulo: Makron, p. 29.

As cinco decisões-chave relacionam-se para resultar em uma governança de Tl eficaz, em que cada uma representa aspectos importantes que devem ser observados dentro da TI. As decisões sobre princípios de TI explicitam os objetivos empresariais da $\mathrm{Tl}$ e estabelecem diretrizes para todas as demais decisões. As decisões sobre a arquitetura de TI convertem os princípios de $\mathrm{Tl}$ em requisitos de integração e padronização e, então, delineiam um guia técnico para prover as capacidades necessárias. As decisões relativas aos investimentos e à priorização da TI mobilizam recursos para converter princípios em sistemas. Decisões 
sobre infraestrutura e aplicações podem fluir de princípios, da arquitetura e de critérios de investimento.

Na Matriz de Arranjos de Governança de TI proposta por Weill e Ross (2006), as decisões (apresentadas em colunas) são cruzadas com os arquétipos (dispostos em linhas), descrevendo as combinações de pessoas que possuem os direitos decisórios ou contribuem para a tomada de cada decisão-chave de TI. Os arquétipos políticos identificados pelos autores são classificados em: Monarquia de negócio, Monarquia de TI, Feudalismo, Federalismo, Duopólio de TI e Anarquia.

A Monarquia de negócio é constituída por executivos de negócios ou executivos individuais $(\mathrm{CxOs})$. Inclui também comitês de executivos seniores de negócios podendo incluir o $\mathrm{ClO}$. Exclui executivos de $\mathrm{Tl}$ que atuem independentemente. A Monarquia de $\mathrm{TI}$ é composta por indivíduos ou grupos de executivos de TI. O Feudalismo é formado por líderes das unidades de negócio, detentores de processos-chave ou seus delegados. O Federalismo é constituído por executivos do nível de diretoria (c-level) e grupos de negócios (processos ou unidades de negócios), incluindo executivos de TI como participantes adicionais. O Duopólio de $\mathrm{TI}$ são os executivos de $\mathrm{TI}$ e algum outro grupo ( $\mathrm{CxO}$ s ou os líderes de unidades de negócio ou os líderes de processos). Por fim, a Anarquia é o arquétipo que representa cada usuário de forma individual (Weill \& Ross, 2006).

A Tabela 2 mostra as combinações dos arquétipos políticos que representam as pessoas que possuem os direitos decisórios ou contribuem para a tomada de decisão da TI:

Tabela 2

Principais participantes nos arquétipos de GTI

\begin{tabular}{lccc}
\hline & Executivos de diretoria & $\begin{array}{c}\text { Tl corporativa e/ou das } \\
\text { unidades de negócio }\end{array}$ & $\begin{array}{c}\text { Líderes das unidades de } \\
\text { negócio }\end{array}$ \\
\hline Monarquia de negócio & $\checkmark$ & $\checkmark$ & $\checkmark$ \\
Monarquia de TI & $\checkmark$ & $\checkmark$ & $\checkmark$ \\
Feudalismo & $\checkmark$ & & $\checkmark$ \\
Federalismo & $\checkmark$ & $\checkmark$ & $\checkmark$ \\
Duopólio de TI & $\checkmark$ & $\checkmark$ &
\end{tabular}

Nota. Adaptada de "Governança de tecnologia da informação: Como as empresas com melhor desempenho administram os direitos decisórios de TI na busca por resultados superiores," por P. Weill e J. W. Ross, 2006, São Paulo: Makron, p. 62. 
Na pesquisa realizada por Weill e Ross (2006), cujo objetivo foi verificar como a empresa típica governa a TI em 256 empresas pertencentes a 23 países, identificou-se que a Monarquia de negócio está propensa a aceitar contribuições das demais fontes para as decisões-chave de $\mathrm{Tl}$, enquanto que na Monarquia de $\mathrm{TI}$ os profissionais da $\mathrm{TI}$ tomam as decisões desta, existindo, dessa forma, o poder de impor estratégias e arquitetura de TI.

Quanto ao Feudalismo, o modelo não se mostrou comum e não facilita a tomada de decisões da empresa como um todo. Já no Federalismo, a tomada de decisões coordenada envolve o centro e as unidades de negócio, possibilitando o equilíbrio das responsabilidades e cobranças, porém, é o mais difícil arquétipo para a tomada de decisão em razão do conflito de interesses entre as partes relacionadas.

Por outro lado, o Duopólio de TI difere do modelo Federalista no sentido de que o arranjo Federalista tem sempre a representação tanto corporativa quanto local, ao passo que o Duopólio tem uma ou outra, nunca ambas, e inclui invariavelmente profissionais de TI. É popular, mais simples e mais utilizado. A Anarquia é a tomada de decisão individual com base em necessidades locais. Pode ser ruim para a TI, uma vez que proporciona uma visão singular, não do todo.

\subsection{ESTUDOS CIENTÍFICOS RELACIONADOS}

De acordo com pesquisas nas bases de dados CAPES e EBSCOHost, poucos estudos científicos recentes foram identificados quanto à temática de arquétipos nos direitos decisórios elou de contribuição às decisões de TI. Os trabalhos encontrados mais atuais pertencem ao ano de 2013. Essa constatação corrobora a afirmação de Mendonça et al. (2013) sobre a existência de pesquisas sobre GTI, porém, com escassez de estudos de caso que analisem o processo decisório na área de TI.

A Tabela 3 expõe a relação de pesquisas localizadas relacionadas ao tema, indicando os autores, objetivo dos estudos, metodologia empregada e principais resultados encontrados: 
Tabela 3

Estudos científicos relacionados

\begin{tabular}{|c|c|c|c|}
\hline Autor/Ano & Objetivo & Metodologia & Principais resultados \\
\hline $\begin{array}{l}\text { Assis e } \\
\text { Laurindo } \\
\text { (2010) }\end{array}$ & $\begin{array}{l}\text { Investigar o impacto da GTI } \\
\text { sobre a Gestão de TI. }\end{array}$ & $\begin{array}{l}\text { Estudo de } \\
\text { caso }\end{array}$ & $\begin{array}{l}\text { Domínio de decisão Empresa A: Princípios da TI } \\
\text { (Federalista); Arquitetura de TI (Federalista); } \\
\text { Infraestrutura (Monarquia de TI); Necessidades } \\
\text { específicas do negócio (Federalista); Investimento } \\
\text { e priorização em TI (Federalista). Domínio de } \\
\text { decisão Empresa B: Princípios de TI (Federalista); } \\
\text { Arquitetura de TI (Monarquia de TI); Infraestrutura } \\
\text { (Monarquia de TI); Necessidades específicas do } \\
\text { negócio (Federalista); Investimento e priorização } \\
\text { em TI (Federalista). }\end{array}$ \\
\hline
\end{tabular}

Analisar a percepção de gestores de negócio e de TI Pereira et sobre a estrutura de GTI na al. (2013) tomada de decisão para a prestação de um e-serviço público.

Identificar o perfil dos dirigentes de TI de uma

Mendonça et al. (2011) capital brasileira, sua percepção com relação estratégia de negócio e TI e de decisão com relação à alocação dos direitos decisórios de TI.

Avaliar a participação dos gestores de tecnologia da informação de organizações

Mendonça públicas e privadas no et al. processo de alinhamento de (2013) Tl e tomadas de decisões estratégicas organizacionais com base na Matriz de Arranjo de Governança de TI.
Estudo de caso

A tomada de decisão é para implementação de um e-serviço público, é influenciada pelo arquétipo de decisão, definida como monarquia de negócio. Tomada de decisão única.

40\% das empresas não utilizam as melhores práticas em TI (ITIL, Cobit, Pmbok, BSC, CMMI, entre outras). Quanto à matriz de decisão:

Survey Princípios de TI (Monarquia de TI); Arquitetura de TI (Monarquia de TI); Infraestrutura de TI (Monarquia de TI); Necessidades de aplicações em negócios (Monarquia de TI); Investimentos em TI (Duopólio).

Monarquia de TI prevaleceu em todas as decisõeschave nas empresas públicas e privadas, exceto em Investimentos em $\mathrm{Tl}$ na empresa pública refere-se a Duopólio e na privada refere-se à Monarquia de negócio.

Conforme a Tabela 3, as pesquisas identificadas, limitadas às bases de dados consultadas, dividem-se em estudos de caso e surveys, sendo todos os trabalhos de nacionalidade brasileira. Percebe-se que os principais resultados quanto à forma como as empresas decidem e governam a TI não são totalmente convergentes, ou seja, em algumas decisões-chave as práticas decisórias utilizadas pelas companhias diferem quanto ao arquétipo predominante. Pode-se verificar que Monarquia de TI, Duopólio, Monarquia de negócio e Federalismo são as tipologias decisórias mais recorrentes.

\section{METODOLOGIA}

\subsection{CLASSIFICAÇÃO DA PESQUISA}


A pesquisa quanto ao seu objetivo se caracteriza como descritiva. De acordo com Collis e Hussey (2005), o estudo descritivo descreve o comportamento dos fenômenos, sendo utilizado para identificar e obter informações sobre as características de um determinado problema ou questão.

A estratégia de pesquisa utilizada foi o estudo de caso. Segundo Yin (2015), o estudo de caso pode ser tratado como importante estratégia metodológica para a pesquisa, pois permite ao investigador o aprofundamento com relação ao fenômeno estudado.

Quanto à abordagem do problema, o estudo delineia-se como qualitativo. Collis e Hussey (2005) argumentam que o método qualitativo é mais subjetivo e envolve examinar e refletir as percepções para obter um entendimento de atividades sociais e humanas.

\subsection{PROCEDIMENTOS DE COLETA E TRATAMENTO DOS DADOS}

A coleta de dados ocorreu por meio de entrevistas semiestruturadas realizadas com a Gerente da área de TI, a Gerente de Controladoria e a responsável pela consolidação do orçamento na empresa. As entrevistas foram pautadas conforme literatura disseminada por Weill e Ross (2006), conforme Apêndice A. O objetivo das entrevistas foi promover a análise de forma aprofundada quanto à participação de gestores nos direitos decisórios ou de contribuição nas estratégias de TI.

Além das entrevistas, houve a observação direta e documental de processos orçamentários a fim de corroborar o entendimento sobre o poder decisório dos gestores quanto à utilização de recursos vinculados à TI. Para investigação, a unidade de análise escolhida foi uma empresa de grande porte no Estado do RS com forte representatividade econômica para a região. A escolha da empresa ocorreu em razão da acessibilidade dos dados.

Os dados foram tratados de forma descritiva e qualitativa, transcritos para o software Microsoft Word $2010^{\circledR}$. A análise foi complementada com a comparação dos resultados encontrados com aqueles apresentados na Tabela 3, bem como com o estudo de Weill e Ross (2006). Os dados foram analisados em triangulação. Para Collis e Hussey (2005), a triangulação das informações proporciona maiores validade e confiabilidade dos dados comparadas a uma única visão metodológica.

\section{ANÁLISE E DISCUSSÃO DOS RESULTADOS}

O objetivo desta pesquisa foi analisar a participação de gestores nos direitos decisórios e de contribuição nas estratégias de Tl em uma empresa de grande porte no Estado do RS. Dessa 
forma, os dados foram estruturados sob dois aspectos fundamentais que atendem à Matriz de Arranjos de Governança de Tl: quem toma a decisão e quem contribui para a decisão.

As cinco decisões críticas de TI Princípios de TI, Arquitetura de TI, Infraestrutura de TI, Necessidades de aplicações de negócio e Investimentos e priorização de TI foram analisadas com os principais participantes nos arquétipos de GTI. Os resultados encontrados são descritos a seguir.

\subsection{PRINCÍPIOS DE TECNOLOGIA DA INFORMAÇÃO (TI)}

Os princípios de TI são um conjunto relacionado de declarações de alto nível sobre como a Tecnologia da Informação é utilizada no negócio. Uma vez articulados, os princípios de TI tornam-se parte do léxico administrativo da empresa. $O$ principal indicador de um conjunto efetivo de princípios de Tl é uma trilha clara de evidências que conduza os princípios do negócio aos princípios de TI (Weill e Ross, 2006).

Investigaram-se na empresa analisada as decisões que envolvem políticas, normas e diretrizes específicas de $\mathrm{Tl}$, de forma a traduzir as estratégias de negócio em estratégias de TI. Nesse sentido, verificou-se que tais decisões críticas para o alinhamento entre negócio e TI são debatidas, apoiadas, discutidas, recusadas e/ou aprimoradas por um grupo composto da presidência, vice-presidência, diretoria ou gerência. A TI aceita as sugestões vindas desse grupo, discute, apoia ou recusa determinadas questões, a fim de proporcionar a melhoria do negócio.

Dessa forma, compreende-se que com relação a decisões vinculadas aos princípios de $\mathrm{TI}$, a empresa estudada caracteriza-se, entre os principais arquétipos de GTI, como Duopólio de TI. O resultado encontrado corrobora o estudo de Weill e Ross (2006), que da mesma forma encontraram o Duopólio de TI como arquétipo predominante. Por outro lado, diverge dos achados em estudos anteriores, nos quais o arquétipo para decisão foi identificado como Federalista (Assis e Laurindo, 2010), Monarquia de Negócio (Pereira et al., 2013) e Monarquia de TI (Mendonça et al., 2011; Mendonça et al., 2013).

Ainda sobre os Princípios de Tl, indagou-se sobre a contribuição a decisões no que se refere ao comportamento desejável tanto para profissionais quanto para usuários de TI. Esse comportamento é definido por Weill e Ross (2006) como estímulo da GTI a comportamentos consistentes com a missão, a estratégia, os valores, as normas e a cultura da organização. Um exemplo de comportamento desejável seria a reutilização da capacidade existente de $\mathrm{Tl}$, ao invés da compra de novos componentes para o sistema com capacidade similar aos já utilizados. Nesse aspecto, a gerente de TI respondeu que:

Dependendo da situação monetária que a empresa está passando, as próprias áreas de negócio sugerem e entendem a necessidade de reaproveitar recursos, mas existem situações que 
inevitavelmente é necessária a reposição de equipamentos, por motivos de obsolescência. Desta forma a Tl orienta a troca de componentes a fim de evitar a inoperância do sistema (Informação verbal, 5 de novembro de 2015).

Percebe-se que o comportamento desejável está presente nas unidades de negócio pertencentes à empresa, e que essas unidades são as que mais contribuem para a tomada de decisão da TI. Esta orienta as unidades de negócio, uma vez que ela faz parte do grupo decisório dos Princípios de TI, mas as informações que auxiliam as decisões advêm de cada centro de negócios da empresa. Desse modo, quanto à contribuição para a tomada de decisão aos Princípios de TI, a companhia pode ser caracterizada como Feudalismo. Esse achado difere do resultado da pesquisa de Weill e Ross (2006), em que os autores encontraram como maior contribuinte o arquétipo Federalismo. Os demais estudos não analisaram a questão da contribuição para a tomada de decisão.

\subsection{ARQUITETURA DE TECNOLOGIA DA INFORMAÇÃO (TI)}

Na decisão-chave Arquitetura de TI, indagou-se quem decide sobre a organização lógica dos dados, aplicações e infraestruturas para obter a padronização e a integração de processos na empresa. A padronização e a integração moldam as capacidades de TI.

A padronização de processos proporciona previsibilidade e eficiência por meio de uma maneira única e consistente de fazer as coisas. Já a integração dos processos permite que múltiplas unidades de negócio apresentem uma face única aos clientes, ou mudem ininterruptamente de uma função para outra.

Identificou-se que tanto a decisão quanto a contribuição sobre a organização lógica dos dados, aplicações e infraestruturas são tomadas exclusivamente pelos executivos de TI. Conforme a gerente de TI:

Esta decisão é tomada em sua totalidade atualmente pela TI, por razão de falta de conhecimento por parte das áreas de negócio.

Na empresa, quem contribui para estas decisões é a área de $\mathrm{Tl}$, encontrando alternativas para a organização dos dados e infraestrutura. Eventualmente, empresas fornecedoras de serviços de TI, contratadas pela empresa, contribuem para estas decisões também (Informação verbal, 5 de novembro de 2015).

Com relação a escolhas técnicas, como, por exemplo, acordos com fornecedores, segurança empresarial e processamento de dados, as decisões são tomadas por executivos 
de $\mathrm{TI}$ conjuntamente com algum outro grupo ( $\mathrm{ClO}$ ou líderes de unidades de negócio, ou líderes de processos). Essas escolhas são decididas primeiramente pela $\mathrm{Tl}$, em razão das demandas vindas das áreas de negócio, e depois passam por decisões de outros líderes da empresa, principalmente para decisões financeiras. A contribuição para a tomada de decisão relativa a escolhas técnicas cabe somente a indivíduos ou grupos de executivos de TI.

De forma geral, entende-se que para a Arquitetura de $\mathrm{Tl}$ os direitos decisórios e de contribuição nas estratégias de TI se classificam, respectivamente, em Duopólio de TI e Monarquia de TI. Os resultados contrariam o estudo de Weill e Ross (2006), o qual obteve exatamente o inverso, ou seja, Monarquia de TI para decisão e Duopólio de TI para contribuição. Os estudos empíricos descritos na Tabela 3, em maioria, corroboram os achados de Weill e Ross.

\subsection{INFRAESTRUTURA DE TECNOLOGIA DA INFORMAÇÃO (TI)}

A infraestrutura é a base da capacidade planejada de $\mathrm{Tl}$, tanto para capacidade técnica quanto humana disponível em todo o negócio, na forma de serviços compartilhados e confiáveis, e utilizada por aplicações múltiplas (Weill e Ross, 2006). Componentes tecnológicos como computadores, impressoras, pacotes de software para bancos de dados e sistemas operacionais são convertidos em serviços comuns úteis por meio de uma infraestrutura humana de TI composta por conhecimento, habilidades, padrões e experiência.

Os serviços de infraestrutura podem incluir serviços de rede de telecomunicações, a provisão e o gerenciamento de computação em larga escala (servidores), o gerenciamento da base de dados compartilhada de clientes, a expertise em pesquisa e desenvolvimento (para identificar a utilidade de tecnologias emergentes para o negócio), e uma intranet para toda a empresa. Esses serviços podem ser realizados pela empresa ou terceirizados.

Nesse contexto, verificou-se o poder decisório referente aos serviços de rede de telecomunicações, provisão e gerenciamento de computadores, gerenciamento de dados e intranet. Identificou-se que tais aspectos são decididos pelo grupo de presidência, vicepresidência, diretoria ou gerência com a Tl, estabelecendo Duopólio de TI.

Esse resultado difere dos encontrados em estudos anteriores, nos quais o arquétipo para decisão quanto à infraestrutura de Tl, em suma, caracterizou-se como Monarquia de TI (Assis \& Laurindo, 2010; Mendonça, 2011; Mendonça, 2013; Weill \& Ross, 2006).

Além da decisão sobre os elementos que configuram a infraestrutura de Tl, investigouse entre os arquétipos de GTI, quais mais poderiam contribuir para a tomada de decisão. Evidenciou-se que quem mais contribui é a própria área de TI. Dessa forma, a contribuição 
quanto a itens relacionados à infraestrutura de TI pode ser identificada como Monarquia de TI. Para Weill e Ross (2006), nesse aspecto, quem mais contribui para a decisão é o Federalismo.

\subsection{NECESSIDADES DE APLICAÇÕES DE NEGÓCIO}

As necessidades de aplicações de negócio consistem na especificação de aplicações de TI adquiridas no mercado ou desenvolvidas internamente. A identificação dessas necessidades costuma possuir dois objetivos conflitantes: a criatividade e a disciplina.

De acordo com Weill e Ross (2006), pela criatividade se identificam maneiras novas e mais eficazes de gerar valor para os clientes por meio da $\mathrm{Tl}$, envolvendo aplicações de negócio que deem suporte a objetivos de negócio estratégicos e facilitem experimentos de negócios. A disciplina consiste na integridade arquitetônica, assegurando que as aplicações aproveitem e amplifiquem a arquitetura já estabelecida na empresa, preservando seus princípios. A disciplina, segundo os autores, também evolve foco, comprometendo os recursos necessários para concretizar metas de projetos e negócios.

$\mathrm{Na}$ empresa objeto deste estudo investigaram-se as necessidades de aplicações de negócios no envolvimento da identificação de processos centrais e a determinação de mudanças nos sistemas e processos capazes de trazer benefícios significativos à empresa. Quanto a essa questão, a gerente de TI expôs que a decisão ocorre entre presidência, vicepresidência, diretoria ou gerência, além de executivos de TI. Diante da mesma questão, porém pela perspectiva de contribuição para a tomada de decisão, a gerente de TI relatou que quem mais contribui nesse aspecto é a área de TI. Perante essas afirmações, evidenciamse o Duopólio de TI para a decisão e a Monarquia de TI para a contribuição.

Entretanto, quando questionado sobre a designação de responsabilidades pela mudança organizacional associada a um projeto de $\mathrm{TI}$, identificou-se a decisão por meio dos executivos da diretoria, das unidades de negócio e área de $\mathrm{Tl}$, e quem mais contribui para essa decisão é o grupo de presidência, vice-presidência, diretoria ou gerência e executivos de TI. Nesse sentido, a decisão caracteriza-se por Federalismo e a contribuição por Duopólio de TI.

Percebe-se que não há um consenso entre qual dos arquétipos de GTI possui maior participação para tomada de decisão e para contribuição a essa decisão. Nota-se, entretanto, que a atuação da área de Tl é constante em qualquer uma das situações expostas.

Com relação à comparação com estudos anteriores, os resultados convergem com o estudo de Weill e Ross (2006), que identificaram quanto às decisões de necessidades de aplicações de negócio uma mescla entre Federalismo e Duopólio de TI. o que não se repete para a contribuição, uma vez que para os autores a predominância é o arquétipo Federalismo, enquanto que neste estudo se detectou Monarquia de TI e Duopólio de TI. 


\subsection{INVESTIMENTOS E PRIORIZAÇÃO DE TECNOLOGIA DA INFORMAÇÃO (TI)}

As decisões sobre investimentos em TI devem determinar quanto a empresa pode gastar, em que elementos ela deve gastar e como reconciliar as necessidades de diferentes grupos de interesses. Conforme Weill e Ross (2006), o uso de benchmarks é apenas o ponto de partida, uma vez que altos administradores se concentram no papel estratégico que a TI desempenha na organização e estabelecem um nível de custeio para toda a empresa, habilitando a tecnologia a atingir seu objetivo.

Diferentes contextos estratégicos fazem com que as empresas tenham diferentes níveis de investimentos em TI. A administração do portfólio de investimentos permite aos tomadores de decisão alinhar seus portfólios com a estratégia da empresa, balanceando riscos e retorno.

Com relação aos investimentos e priorização de TI quanto à decisão de gastar, em que gastar e como reconciliar as necessidades de diferentes grupos de interesses, identificouse na empresa analisada que os responsáveis pela decisão são os executivos do nível de diretoria e os grupos de negócios (processos ou unidades de negócio), incluindo os executivos de TI como participantes adicionais.

A atuação conjunta dessas áreas para tomada de decisão caracteriza, nesse contexto, que o arquétipo predominante é o Federalismo. Esse resultado corrobora o estudo de Assis e Laurindo (2010), em que os autores investigaram duas empresas e ambas faziam uso do arquétipo Federalista para decisões em investimentos e priorizações de TI. Da mesma forma, o resultado vai ao encontro do estudo de Weill e Ross (2006), em que três arquétipos foram destacados como os mais utilizados para investimentos em TI, entre eles o Federalista. Em contrapartida, as pesquisas de Mendonça et al. (2011), Mendonça et al. (2013) e Pereira et al. (2013) divergem desse resultado, sendo detectados como predominantes os arquétipos Monarquia de Negócio e Duopólio de TI.

Quanto ao aspecto de quem mais contribui para a decisão sobre investimentos em $\mathrm{TI}$, constatou-se que indivíduos ou grupos de executivos de TI é quem possuem essa função. Desse modo, a contribuição classifica-se como Monarquia de TI, contrariando a pesquisa de Weill e Ross (2006), na qual identificam para esse item o Federalismo. 


\subsection{MATRIZ DE ARRANJOS DE GOVERNANÇA DE TI E ARQUÉTIPOS POLÍTICOS}

De acordo com os dados dispostos nas subseções 4.1 a 4.5, A Tabela 4 apresenta a Matriz de Arranjos de Governança de TI e Arquétipos Políticos da presente pesquisa:

Tabela 4

Matriz de Arranjos de Governança e Arquétipos Políticos

\begin{tabular}{|c|c|c|c|c|c|c|c|c|c|c|}
\hline & \multicolumn{2}{|c|}{$\begin{array}{l}\text { Princípios } \\
\text { de TI }\end{array}$} & \multicolumn{2}{|c|}{$\begin{array}{c}\text { Arquitetura } \\
\text { de TI }\end{array}$} & \multicolumn{2}{|c|}{$\begin{array}{l}\text { Infraestrutura } \\
\text { de } \mathrm{TI}\end{array}$} & \multicolumn{2}{|c|}{$\begin{array}{l}\text { Necessidades } \\
\text { de aplicação } \\
\text { de negócio }\end{array}$} & \multicolumn{2}{|c|}{$\begin{array}{c}\text { Investimentos } \\
\text { em TI }\end{array}$} \\
\hline & $\mathrm{C}^{*}$ & $D^{*}$ & $\mathrm{C}^{*}$ & $D^{*}$ & $\mathrm{C}^{*}$ & $D^{*}$ & $\mathrm{C}^{*}$ & $D^{*}$ & $\mathrm{C}^{*}$ & $D^{*}$ \\
\hline \multicolumn{11}{|c|}{ Monarquia de Negócio } \\
\hline Monarquia de TI & & & $x$ & & $x$ & & $X$ & & $\mathrm{X}$ & \\
\hline Feudalismo & $\mathrm{X}$ & & & & & & & & & \\
\hline Federalismo & & & & & & & & $x$ & & $\mathrm{X}$ \\
\hline Duopólio de TI & & $X$ & & $X$ & & $X$ & $x$ & $X$ & & \\
\hline
\end{tabular}

Conforme destacado na Tabela 4, observa-se que a maioria das decisões-chave relacionadas à Governança de TI é tomada por Duopólio de TI. O Duopólio consiste em decisões estratégicas de TI por meio de executivos de TI com algum outro grupo da empresa, por exemplo, $\mathrm{CxO}$ s ou líderes de unidades de negócios. Com relação à contribuição para a tomada de decisão, percebe-se que o arquétipo predominante é a Monarquia de $\mathrm{Tl}$, ou seja, a participação exclusiva de indivíduos ligados à área de TI. Nota-se, dessa forma, o forte envolvimento de profissionais de TI no processo decisório da empresa estudada.

Essa parceria entre administradores seniores e líderes de TI no processo decisório pode auxiliar o alinhamento entre TI e estratégias de negócios e fornecer expectativas realistas para a TI. Do mesmo modo, pode promover o esclarecimento da estratégia, e assegurar também o comprometimento da unidade de TI com os princípios de negócios. A atuação entre alta gerência e TI se torna favorável, principalmente quando relacionada a questões de negociações comerciais, políticas e tecnológicas, uma vez que a alta gerência estabelece o horizonte estratégico e a área de TI traz as contribuições técnicas e organizacionais.

\section{CONCLUSÃO}

Esta pesquisa analisou a participação de gestores nos direitos decisórios e de contribuição nas estratégias de TI em uma empresa de grande porte no Estado do RS. Para a análise foram considerados os arquétipos políticos de GTI aliados às cinco decisões críticas 
de TI, classificadas como: Arranjos de governança típicos para princípios de Tl; Arranjos de governança típicos para a arquitetura de $\mathrm{Tl}$; Arranjos de governança típicos para estratégias de infraestrutura de Tl; Arranjos de governança típicos para necessidades de aplicações de negócio; e Arranjos de governança típicos para investimentos e priorização de TI.

Os dados foram estabelecidos sob a perspectiva de quem toma a decisão e quem contribui para a decisão, atendendo, dessa forma, à Matriz de Arranjos de Governança de TI proposta por Weill e Ross (2006). De acordo com as informações encontradas, nota-se que a empresa analisada apresenta um comportamento semelhante no que tange ao processo decisório para as cinco decisões críticas.

Percebe-se que a maioria das decisões-chave relacionadas à Governança de TI são tomadas por Duopólio de $\mathrm{Tl}$, e com relação à contribuição para a tomada de decisão, o arquétipo predominante é a Monarquia de TI. Desse modo, entende-se que a participação de gestores nos direitos decisórios e de contribuição nas estratégias de TI da empresa consiste na atuação de executivos de TI com algum outro grupo da empresa, por exemplo, $\mathrm{CxOs}$ ou líderes de unidades de negócios. Verifica-se uma parceria entre administradores seniores e líderes de $\mathrm{TI}$ com vistas ao alinhamento entre Tl e estratégias de negócios.

Os resultados encontrados convergem, em parte, aos principais achados em estudos anteriores, como é o caso dos Princípios de TI e Necessidades de aplicações de negócio (Weill \& Ross, 2006) e Investimentos e priorização de TI ( Assis \& Laurindo, 2010; Weill \& Ross, 2006). Em contrapartida, divergem dos estudos de Mendonça et al. (2011), Mendonça et al. (2013) e Pereira et al. (2013) quanto à forma como as empresas decidem e governam a TI. Pode-se verificar que Monarquia de TI, Duopólio, Monarquia de negócio e Federalismo são as tipologias decisórias mais recorrentes nestes estudos. Em nenhuma das pesquisas foi detectado o uso do arquétipo Anarquia.

A comparação com estudos anteriores sugere que não há um consenso entre qual dos arquétipos de GTI possui maior participação para tomada de decisão e para contribuição a essa decisão. Tal fato pode ser explicado, uma vez que diferentes contextos estratégicos podem fazer com que as empresas tenham diferentes perspectivas sobre princípios, levando a novas abordagens relativas à arquitetura de $\mathrm{Tl}$, infraestrutura de $\mathrm{Tl}$, necessidades de aplicações de negócios e investimentos em TI.

Como recomendação para estudos futuros, sugere-se a continuidade de pesquisas que explorem os direitos decisórios e de contribuição nas estratégias de Tl, a fim de corroborar o entendimento sobre elementos que tornam a Governança de Tecnologia da Informação eficaz. Da mesma forma, tornam-se interessantes estudos que relacionem arquétipos políticos e decisões-chave de Tl a itens como desempenho, funcionamento de arranjos de governança ou riscos associados a modelos de Governança de TI. 


\section{REFERÊNCIAS}

Affeldt, F. S., \& Vanti, A. A. (2009, Junho). Alinhamento estratégico de tecnologia da informação: Análise de modelos e propostas para pesquisas futuras. Journal of Information Systems and Technology Management, 6(2), 203-226.

Albertin, A. L., \& Albertin, R. M. M. (2008, Março/Abril). Benefícios do uso de tecnologia de informação para o desempenho empresarial. Revista de Administração Pública, 42(2), 275-302.

Arshad, Y., Ahlan, A. R., \& Ajayi, B. A. (2014, January). Intelligent IT governance decision-making support framework for a developing country's public university. Intelligent Decision Technologies, 8(2), 131-146.

Assis, C. B., \& Laurindo, F. J. B. (2010). Governança de Tl e seu impacto na gestão de TI. Anais do Encontro Nacional de Engenharia de Produção, São Carlos, São Paulo, 30.

Barbosa, C., Araújo, D., \& Torres, I. (2011, Junho). Governança de TI utilizando as práticas da ITIL. Tecnologias em Projeção, 2(1), 34-38.

Bin-Abbas, H., \& Bakry, S. H. (2014, March). Assessment of IT governance in organizations: A simple integrated approach. Computers in Human Behavior, 32, 261-267.

Collis, J., \& Hussey, R. (2005). Pesquisa em administração: Um guia prático para alunos de graduação e pós-graduação. Porto Alegre: Bookman.

Duarte, F. da S., Kipper, L. M., Paz, F. F., \& Mariani, B. B. (2014, Dezembro). A contribuição da TI como ferramenta na gestão de negócios: Um estudo de caso de uma empresa no ramo tecnológico localizada no município de Dom Pedrito/RS. Tecno-Lógica, 18(2), 103 114.

Fernandes, A. A., \& Abreu, V. F. (2014). Implantando a Governança de Ti-: Da estratégia à Gestão de Processos e Serviços. São Paulo: Brasport.

Fink, K., \& Ploder, K. (2008, January). Decision Support Framework for the Implementation of IT-Governance. Proceedings of the Annual Hawaii International Conference on System Sciences, Hawaii, 41.

Fresneda, P. S. V. (1998, Janeiro/Março). Transformando organizações públicas: A tecnologia da informação como fator propulsor de mudanças. Revista do Serviço Público, 9(1), 71-91. 
Hiekkanen, K., Mykkanen, J., Korhonen, J. J., Patricio, E., Collin, J., \& He-lenius, M. (2013, November). Governance, Decision Making and IT Capabilities. Proceedings of the European Conference on Management Leadership and Governance: ECMLG 2013, Klagenfurt, Austria, 9.

IT Governance Institute. (2012). ISACA. Recuperado de http://www.isaca.org/

IT Governance Institute. 2007. Recuperado de http://www.itgi.org

Klumb, R., \& Azevedo, B. M. de. (2014, Abril). A percepção dos gestores operacionais sobre os impactos gerados nos processos de trabalho após a implementação das melhores práticas de governança de TI no TRE/SC. Revista de Administração Pública, 48(4), 961982.

Luciano, E. M., \& Testa, M. G. (2011). Controles de governança de tecnologia da informação para a terceirização de processos de negócio: Uma proposta a partir do Cobit. Journal of Information Systems and Technology Management, 8(1), 238-262.

Lunardi, G. L., Becker, J. L., \& Maçada, A. C. (2012, Maio/Agosto). Um estudo empírico do impacto da governança de TI no desempenho organizacional. Produção, 22(3), 612-624.

Mendonça, C. M. C. de, Guerra, L. C. B., Souza, M. V. de, Neto, \& Araujo, A. G. de. (2013, Março/Abril). Governança de tecnologia da informação: Um estudo do processo decisório em organizações públicas e privadas. Revista Administração Pública, 47(2), 443 468.

Mendonça, C. M. C. de, Souza, M. V. de, Neto, \& Guerra, L. C. B. (2011, Setembro). O Perfil dos Dirigentes de TI de Uma Capital Brasileira e Sua Percepção Com Relação a Estratégia e Arranjos de Governança de TI. Encontro nacional de pós-graduação e pesquisa em administração, 35(1), 1-17.

Moura, W. V., Lima, A. M. de, Pinto, R. G. S., \& Rocha, M. G. da S. (2018, Outubro/Dezembro). Benefícios da tecnologia da informação para as estratégias empresariais: Uma revisão integrativa. Revista Ciência \& Saberes-Facema, 3(4), p. 732-739.

Parolia, N., Jiang, J. J., Chen, J. V., \& Klein, G. (2015, October). Conflict resolution effectiveness on the implementation efficiency and achievement of business objectives in it programs: A study of it vendors. Information and Software Technology, 66, 30-39.

Pereira, G. V., Macadar, M. A., \& Daniel, V. M. (2013, Março/Agosto). Governança de TI na prestação de um e-serviço público. Revista Eletrônica de Sistemas de Informação, 12(2), 1-24. 
Putz, R. B. Z, Rasoto, V. I., \& Ishikawa, E. (2017, July). Brazilian federal universities information technology governance: An analysys of the strategic alignment dimension. Proceedings of the Information Systems and Technologies (CISTI), Iberian Conference on, Lisbon, Portugal, 12.

Santos, J. W., Filho. (2018, Fevereiro). Governança de TI: Análise das Contribuições de Mecanismos Privados no Gerenciamento Público de TI. Interfaces Científicas-Exatas e Tecnológicas, 2(3), 71-84.

Sêmola, M. Gestão da segurança da informação. Rio de Janeiro: Elsevier, 2014.

Sortica, E. A., \& Graeml, A. R. (2009, Janeiro/Março). Critérios de efetividade da governança de TI: o caso de uma empresa brasileira do setor de telecomunicações. Revista de Administração FACES Journal, 8(1), 11-30.

Tarouco, H. H., \& Graeml, A. R. (2011, Janeiro/Março). Governança de tecnologia da informação: Um panorama da adoção de modelos de melhores práticas por empresas brasileiras usuárias. Revista de Administração, 46(1), 7-18.

Thompson, S., Ekman, P., Selby, D., \& Whitaker, J. (2014, March). A model to support IT infrastructure planning and the allocation of IT governance authority. Decision Support Systems, 59, 108-118.

Weill, P., \& Ross, J. W. (2006). Governança de tecnologia da informação: Como as empresas com melhor desempenho administram os direitos decisórios de TI na busca por resultados superiores. São Paulo: Makron.

Yin, R. K. (2015). Estudo de Caso: Planejamento e métodos. Porto Alegre: Bookman. 


\section{APÊNDICE A-Questões de pesquisa}

As questões de pesquisa foram pautadas conforme obra de Weill e Ross (2006). O objetivo das entrevistas foi promover a análise quanto à participação de gestores nos direitos decisórios ou de contribuição nas estratégias de TI. Referem-se aos arranjos: Princípios de Tl; Arquitetura de TI; Infraestrutura de Tl; Necessidades de aplicação ao negócio; e Investimento e priorização de TI.

1) As decisões que envolvem políticas, normas e diretrizes específicas de $\mathrm{Tl}$, para traduzir as estratégias de negócio em estratégias de TI, são discutidas, debatidas, apoiadas, recusadas elou aprimoradas por quem?

2) Quem mais contribui para a definição do comportamento desejável (exemplo: reutilizar as capacidades existentes de TI ao invés de comprar novos componentes de sistema) tanto para profissionais quanto para usuários da Tecnologia da Informação?

3) A decisão de organização lógica dos dados, aplicações e infraestruturas para obter a padronização e a integração de processos na empresa é definida por quem? Quem mais contribui para essa decisão?

4) As escolhas técnicas (acordos com fornecedores, segurança empresarial, processamento mais barato) são decididas por quem? Quem mais contribui para essa decisão?

5) Os serviços de rede de telecomunicações, provisão e gerenciamento de computadores, gerenciamento de dados, intranet para toda a empresa são decididos por quem? Quem mais contribui para essa decisão?

6) As necessidades de aplicações de negócios que envolvem a identificação de processos centrais e a determinação de mudanças nos sistemas e processos capazes de trazer benefícios significativos à empresa (aproveitar novas oportunidades e evitar a obsolescência) são decididas por quem? Quem mais contribui para essa decisão?

7) Quem decide sobre a designação de responsabilidades pela mudança organizacional associada a um dado projeto de TI? Quem mais contribui para essa decisão?

8) Quem faz a decisão sobre investimentos em TI: quanto gastar, em que gastar, como reconciliar as necessidades de diferentes grupos de interesse? Quem mais contribui para essa decisão?

\section{Como citar este artigo:}

\section{ABNT}

Fontana, Karen Hackbart Souza et al. Direitos decisórios e de contribuição nas estratégias de TI: estudo em uma empresa de grande porte no Estado do RS. RACE, Revista de Administração, Contabilidade e Economia, Joaçaba: Editora Unoesc, v. 18, n. 3, p. 543-564, set./dez. 2019. Disponível em: http://editora.unoesc.edu.br/index.php/race. Acesso em: dia/ mês/ano.

\section{APA}

Fontana, K. H. S., Thiel, G. R., Vanti, A. A., \& Solana, P. G. (2019). Direitos decisórios e de contribuição nas estratégias de TI: Estudo em uma empresa de grande porte no Estado do RS. RACE, Revista de Administração, Contabilidade e Economia, 18(3), 543-564. Recuperado de http://editora.unoesc.edu.br/index.php/race 